\title{
Effect of Friction Pressure on Microstructure and Properties of Friction Welded Joints of Pure Aluminum/304 Stainless Steel
}

\author{
Lizhe ZHAO $^{1}$, Wenbiao GONG $^{1 *}$, Rui ZHU $^{1}$, Mingyue GONG $^{2}$, Heng CUI ${ }^{2}$ \\ ${ }^{1}$ School of Materials Science and Engineering, Changchun Institute of Technology, Changchun, 130012, China \\ ${ }^{2}$ Changchun Railway Bus Co., Ltd., Changchun 130062, P. R. China \\ crossref http://dx.doi.org/10.5755/j02.ms.23410
}

Received 21 May 2019; accepted 27 February 2020

\begin{abstract}
Continuous drive friction welding was used to realize the high quality connection between pure aluminum and 304 stainless steel. The composition of interface micro-zone and mechanical properties of joint were analyzed by scanning electron microscopy (SEM), X-ray diffraction (XRD), tensile test and hardness test. The formation mechanism of intermetallic compound (IMC) during friction welding was discussed. The results show that under the experimental parameters, the joint surface is uneven and two intermetallic compounds, $\mathrm{Fe}_{2} \mathrm{Al}_{5}$ and $\mathrm{FeAl}_{3}$, are formed. With the increase of friction pressure, the mechanical bonding degree of the joint decreases, the metallurgical bonding degree increases, the element diffusion distance increases from 1.4 to $1.9 \mathrm{um}$, the tensile strength of the joint can reach or even higher than that of the base metal on the aluminum side, and the maximum hardness increased from $414 \mathrm{HV}$ to $447 \mathrm{HV}$.

Keywords: pure aluminium, 304 stainless seel, friction welding of dissimilar metals, formation of intermetallic compounds.
\end{abstract}

\section{INTRODUCTION}

The steel-aluminum composite structure has the characteristics of low density and high thermal conductivity of aluminum alloy, and also has the characteristics of high strength and wear resistance of steel, and the application of steel-aluminum composite structure brings great economic benefits. However, since the physical properties of aluminum and its alloys are different from those of stainless steel, and Fe is hardly dissolved in $\mathrm{Al}$, it is easy to produce hard and brittle intermetallic compounds [1], resulting in poor weldability of the two metals. Conventional welding methods such as diffusion welding [2], fusion welding [3, 4], and brazing [5] are used, and the welding time is long and defects such as incomplete penetration, hot cracks, and pores may occur in the joint. Friction welding has the advantages of low interface temperature, fast cooling speed, short welding time, no need to fill materials, etc., avoiding the formation of the above defects, and is an ideal welding method for steel/aluminum dissimilar metal materials [6].

Many scholars have studied the friction welding of steel/aluminum dissimilar metals. For example, Zhang Lina [7] et al. used different processes to connect 2219 aluminum alloy with stainless steel, it was found that elements such as iron and aluminum diffused at the interface to form a transition layer of about 1 micron. And the phenomenon of grain refinement was found on the side of the aluminum substrate. Feng Jian [8] et al. used continuous drive friction welding to achieve the connection between 7A04 aluminum alloy and 304 stainless steel. The thickness of the joint diffusion layer was about $2.5 \mu \mathrm{m}$. Mumin Sahin [9] found the formation of $\mathrm{FeAl}$ and $\mathrm{Fe}_{3} \mathrm{Al}$ at the weld interface, and proposed that the formation of these two intermetallic compounds reduces the tensile strength of the joint. M. Ashfaq et al. [10] found a $5 \mu \mathrm{m}$ thick $\mathrm{Al} / \mathrm{Fe}$ diffusion layer in the 6061 aluminum alloy/304 stainless steel friction welded joint, and found $\mathrm{FeAl}_{3}$ formation at the interface. Masaaki Kimura1 [11] et al. used friction welding to achieve the connection of 6063 aluminum alloy to AISI 304 stainless steel thin-walled tubes and to obtain joints without intermetallic compounds. The above research mainly focused on the microstructure study of aluminum alloy/stainless steel friction welded joints, and did not elaborate on the formation process of intermetallic compounds.

In this paper, the microstructure, mechanical properties and intermetallic compounds of pure aluminum/stainless steel welded joints were analyzed, and the formation order and growth mechanism of intermetallic compounds were discussed in combination with the analysis results.

\section{THE EXPERIMENTAL PROCEDURE}

The materials used in the test were industrial pure aluminum of $\varnothing 22 \times 150 \mathrm{~mm}$ and hot-rolled 304 stainless steel of $\varnothing 20 \times 150 \mathrm{~mm}$. The material composition is shown in Table 1.

Table 1. Main chemical constituents of test materials

\begin{tabular}{|c|c|c|c|c|c|c|}
\hline Materials & $\mathrm{Al}$ & $\mathrm{Si}$ & $\mathrm{Mn}$ & $\mathrm{Ni}$ & $\mathrm{Cr}$ & $\mathrm{Fe}$ \\
\hline Aluminum & Surplus & 0.25 & 0.03 & - & - & 0.35 \\
\hline Steel & - & 0.49 & 1.2 & 8.11 & 18.35 & Surplus \\
\hline
\end{tabular}

The welding equipment used in the experiment was a C-25A-2 continuous drive friction welder. The experimental parameters are shown in Table 2. The aluminum rod was placed in the rotating end and the stainless steel rod in the moving end. The welding form is

\footnotetext{
* Corresponding author. Tel.: +86-13144370145.

E-mail address: 736733387@qq.com (L.Z. Zhao)
} 
shown in Fig. 1. Before the welding, the end face of the test piece was cleaned and wiped with acetone. After welding, the excess base metal was removed by lathe, and the tensile and metallographic samples were cut along the vertical weld by wire cutting.

Table 2. Experimental parameters

\begin{tabular}{|c|c|c|c|c|c|}
\hline $\begin{array}{c}\text { Sample } \\
\text { number }\end{array}$ & $\begin{array}{c}\text { Speed, } \\
\text { r/min }\end{array}$ & $\begin{array}{c}\text { Friction } \\
\text { time, s }\end{array}$ & $\begin{array}{c}\text { Upset } \\
\text { time, s }\end{array}$ & $\begin{array}{c}\text { Friction } \\
\text { pressure, } \\
\mathrm{MPa}\end{array}$ & $\begin{array}{c}\text { Upset } \\
\text { pressure, } \\
\mathrm{MPa}\end{array}$ \\
\hline 1 & 800 & 0.8 & 2 & 0.3 & 1.8 \\
\hline 2 & 800 & 0.8 & 2 & 1.7 & 1.8 \\
\hline
\end{tabular}

The tensile load of the joint was tested by WDW-200 microcomputer controlled electronic universal material testing machine. The metallographic samples were mechanically polished after grinding with different meshes of sandpaper, and the aluminum side was corroded by a mixed acid solution (HF: $\mathrm{HCl}: \mathrm{HNO}_{3}: \mathrm{H}_{2} \mathrm{O}=1: 1.5: 2.5: 95$ ). The interface was observed by jsm-5600lv scanning electron microscope and the components of interface microzone were analyzed by EDS, phase test of the joint were analyzed by $\mathrm{D} / \mathrm{max} 2000 \mathrm{X}$-ray diffractometer. The hardness distribution around the weld was measured by an FM700 microhardness tester with an aluminum side load of $50 \mathrm{~g}$, a steel side load of $100 \mathrm{~g}$, and a loading time of $15 \mathrm{~s}$.

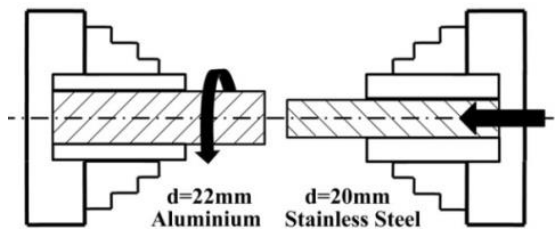

Fig. 1. Schematic diagram of friction welding process

\section{RESULTS AND DISCUSSION}

\subsection{Macroscopic appearance}

The macroscopic morphology of the welded joints under the two sets of parameters is shown in Fig. 2. The flashing edge is mainly produced by the aluminum side, which is continuous and uniform without cracking. The flashing edge is during the welding process, and the thermo plasticized aluminum material is subjected to frictional pressure and upset forging. It is formed by the extrusion of the interface under the action of pressure. The size of the flash of the No. 2 test piece is large, firstly due to the increase of the frictional pressure, which causes more plasticized aluminum to be caused by the "extrusion" interface. Secondly, the size of the flash edge is also related to the heat input. For the friction welding method, Zhong Yan [12] proposed to use the heat flux density to calculate the heat input of the welding interface, which can be expressed as:

$Q=q \times s \times t$,

where $Q$ is the heat input, $\mathrm{J} ; q$ is the heat flux density, $\mathrm{W} / \mathrm{m}^{2}$; $s$ is the friction area, $\mathrm{m}^{2} ; t$ is the friction time, $\mathrm{s}$.

$q=\frac{4}{3} m p_{f} n \eta R_{0} \pi$,

where $q$ is the heat flux density, $\mathrm{W} / \mathrm{m}^{2} ; m$ is the friction coefficient; $P_{f}$ is the friction pressure, $\mathrm{MPa} ; n$ is the rotational speed, r/min; $\eta$ is the frictional thermal efficiency; $R_{0}$ is the friction radius, $\mathrm{m}$.

According to the formula, it can be seen that the heat input of welding is positively correlated with friction pressure. With the increase of friction pressure, the heat input of interface increases, which leads to more aluminum transforming into plastic flow state, and larger flash will be produced under fixed pressure.

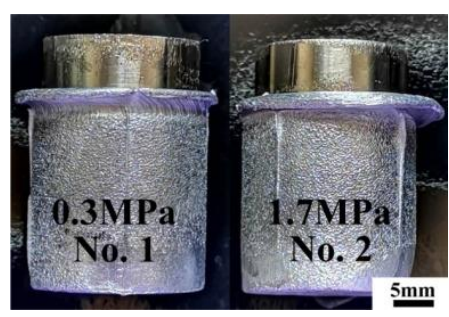

Fig. 2. Macroscopic appearance

\subsection{Interface Microstructure}

By observing the SEM morphology of the two groups of parameters, it can be seen that the interface of the No. 1 specimen has a large undulation, and the mechanical mixing and meshing of the metal on both sides is very obvious, as shown in Fig. 3 a. The interface of the No. 2 test piece was wavy, and the plasticized aluminum material and the steel side interface were closely adhered. No holes were found. The interface of the No. 2 test piece was wavy. The plasticized aluminum material and the steel side interface were closely adhered. No holes were found, and the interface metal fitting was uneven. The mechanical occlusion was lower than that of the No. 1 test piece, as shown in Fig. 3 b. Further enlargement of the weld of No. 2 specimen can observe the intermediate layer of the twolayer structure, the thickness of the intermediate layer is not uniform, the thickest part is about $1.1 \mu \mathrm{m}$, the thinnest part is about $0.3 \mu \mathrm{m}$, and the side contacting with stainless steel is smoother. The side in contact with the pure aluminum has a convex and concave tooth shape as shown in Fig. 3 c.

The welding process can be divided into a friction stage and an upset stage, and the friction stage can be subdivided into two phases, namely an abrasion stage [13] and an adhesive friction stage [14]. At the beginning of welding, the protrusions on the interface wear and shear to generate frictional heat. As the welding process progresses, the metal gradually changes to a plastic state, the abrasion stage changes to the stick friction stage, and the adhesion region expands until the thermoplastic metal expands to the entire interface [15]. In this experiment, the welding time is short. When the friction pressure is small, the interface heat input is insufficient. When the upsetting pressure is applied, the metal plasticization is insufficient, and some interfaces are in the wear stage, thus retaining the form of mechanical interaction bite. When the friction pressure is increased, the interface heat input power is large, the metal is fully plasticized, and the friction state is rapidly changed from the abrasion stage to the stick friction stage, so that the weld interface is relatively smooth. In the abrasion stage, the aluminum side layer fault energy increases, and there is a large amount of dislocation slip between the crystal grains, resulting in uneven grain boundary energy. The larger energy part is preferentially corroded, so the aluminum 
sample No. 1 in the near seam area after the corrosion of the material, as shown in Fig. 3 a. Moreover, the forging pressure is applied when the metal is not fully plasticized, and the joint is prone to generate large residual stress after welding, and there is a tendency of welding crack. No. 2 specimen undergoes the adhesive friction process, and the aluminum material close to the interface undergoes sufficient dynamic recovery and recrystallization [16]. The crystal structure is more stable and the energy between the intergranular boundaries. The difference is small, the corrosion resistance is similar to that of the base metal, so there is no significant difference after corrosion. Fig. $3 \mathrm{~d}$ shows the EDS map. It can be seen that there is diffusion behavior between stainless steel and pure aluminum, and a diffusion layer is formed at the interface.

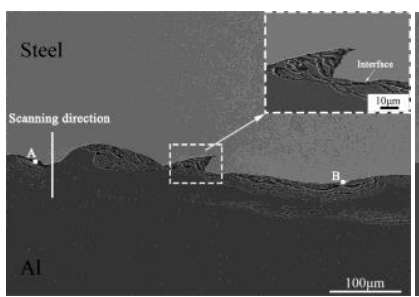

a

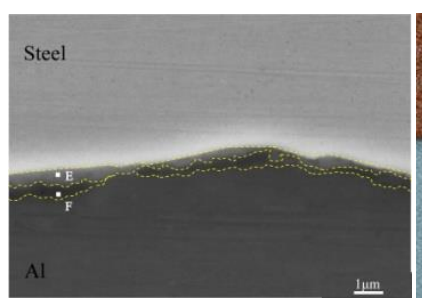

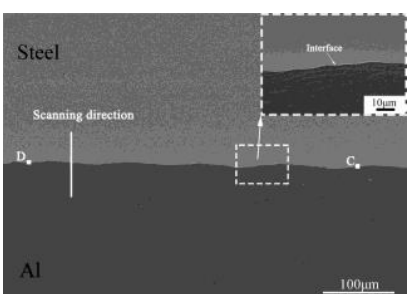

b

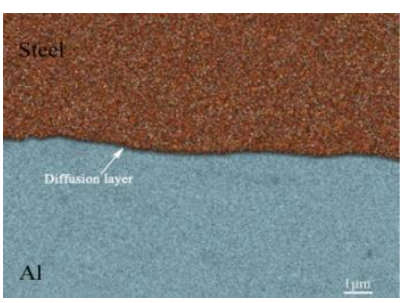

d
Fig. 3. SEM image of interface: a-No. 1 specimen, $b-$ No. 2 specimen; $\mathrm{c}$-intermediate layer; $\mathrm{d}$-EDS map

The results of EDS line scan analysis are shown in Fig. $4 \mathrm{a}$ and $\mathrm{b}$. It can be seen from the line scan results that there is obvious diffusion between the metals. The thickness of the diffusion layer under the two parameters is $1.4 \mu \mathrm{m}$ and $1.9 \mu \mathrm{m}$, respectively. It is indicated that there is diffusion and metallurgical reaction at the interface. At the same time, it can be seen that as the frictional pressure increases, the element diffusion distance increases. The diffusion distance is proportional to the diffusion coefficient, and the relationship between the diffusion coefficient and the temperature obeys Arrhenius' law [17].

\section{$D=D_{0} \exp (-Q / R T)$,}

where $D_{0}$ is the diffusion factor; $Q$ is the activation energy; $R$ is the Boltzmann constant; $T$ is the temperature, ${ }^{\circ} \mathrm{K}$.

Therefore, it can be inferred that there are two main reasons for the increase of the frictional distance: firstly, according to the diffusion theory [18], the increase of the frictional pressure makes the metal gap smaller, the contact between the atoms is closer, and the vacancies in the lattice It is denser with atoms, and the interface atoms are fully activated, which accelerates the diffusion rate between atoms and directly leads to an increase in the diffusion distance of elements. Secondly, due to the increase of the frictional pressure, the interface heat input amount becomes larger, and the diffusion coefficient increases, which indirectly leads to an increase in the element diffusion distance.

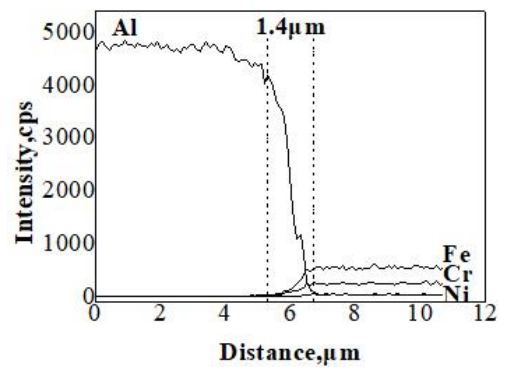

a

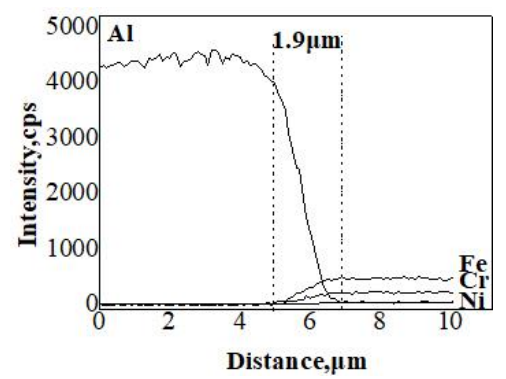

$\mathrm{b}$

Fig. 4. Analysis of SEM line scanning: a-No. 1 specimen; b-No. 2 specimen

Table 3 shows the results of EDS analysis at interfaces A, B, C, D and E of the two test pieces. By calculating the percentage of steel, aluminum and chromium atoms, it can be inferred that two intermetallic compounds $\mathrm{Fe}_{2} \mathrm{Al}_{5}$ and $\mathrm{FeAl}_{3}$ are produced at the interface. There is a small amount of $\mathrm{Cr}$ and $\mathrm{Ni}$ at the interface of the joint. $\mathrm{Cr}$ is involved in the formation of the compound. The $\mathrm{Cr}$ atom will replace part of the Fe atom, which will form a small amount of Al$\mathrm{Fe}(\mathrm{Cr})$ phase, while the $\mathrm{Ni}$ element content is low. The dissolved state exists in the compound, and both the $\mathrm{Cr}$ element and the $\mathrm{Ni}$ element can improve the mechanical properties of the $\mathrm{Fe}-\mathrm{Al}$ intermetallic compound [19].

Table 3. Analysis of SEM point scanning

\begin{tabular}{|c|c|c|c|c|}
\hline Spot & $\mathrm{Al}$, at\% & $\mathrm{Fe}$, at\% & $\mathrm{Cr}$, at\% & Possible phases \\
\hline A & 60.85 & 27.72 & 6.93 & $\mathrm{Fe}_{2} \mathrm{Al}_{5}$ \\
\hline B & 66.36 & 25.29 & 4.36 & $\mathrm{Fe}_{2} \mathrm{Al}_{5}$ \\
\hline C & 96.17 & 0.56 & 0.37 & $\mathrm{Al}$ \\
\hline D & 61.85 & 24.32 & 6.80 & $\mathrm{Fe}_{2} \mathrm{Al}_{5}$ \\
\hline E & 58.67 & 28.46 & 7.20 & $\mathrm{Fe}_{2} \mathrm{Al}_{5}$ \\
\hline F & 70.57 & 19.38 & 5.82 & $\mathrm{FeAl}_{3}$ \\
\hline
\end{tabular}

In order to more accurately judge the type of intermetallic compound, the phase analysis of the joint was carried out, and Fig. 5 shows the results of layer-by-layer XRD analysis of the No. 2 test piece. The analysis of the map by Jade software revealed that there are intermetallic compounds such as $\mathrm{Fe}_{2} \mathrm{Al}_{5}$ and $\mathrm{FeAl}_{3}$ in addition to $\mathrm{Al}$ and $\mathrm{Fe}$ at the interface. This result is consistent with the results of Fukumoto [20] and others, confirming the inference in the previous section.

\subsection{Mechanical properties of the joints}

The tensile test was carried out on the test pieces under the 
two parameters. The test piece No. 1 was broken at the weld, the tensile strength was $78.6 \mathrm{MPa}$, which was about $76 \%$ of the aluminum base metal. The mechanical age of the No. 1 test piece was higher.

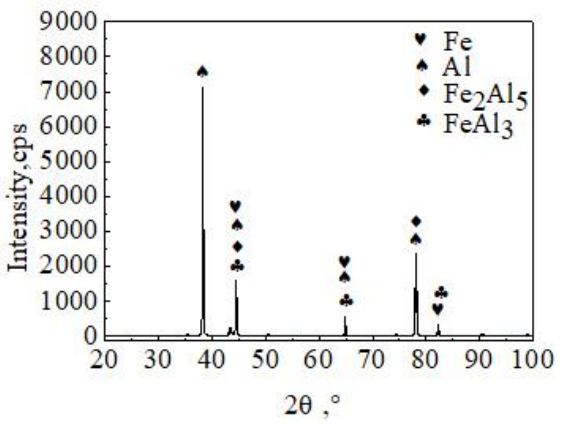

a

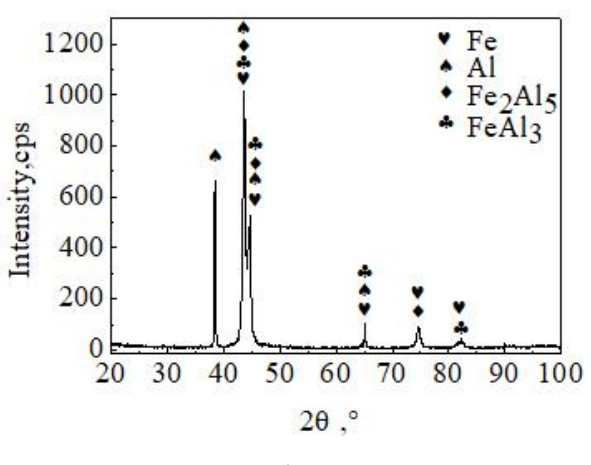

$\mathrm{b}$

Fig. 5. XRD phase analysis: a-XRD analysis of the near aluminium side; $b-X R D$ analysis of the near steel side

However, due to the small frictional pressure, the element diffusion is insufficient, the metallurgical bonding effect is poor, resulting in the joint strength being lower than the aluminum side base metal; the No. 2 test piece is broken on the aluminum side base material, and the tensile strength is $104 \mathrm{MPa}$, indicating that the joint bond strength is close to or even higher than the aluminum side base metal, the larger frictional pressure increases the atomic diffusion distance, the metallurgical reaction is more sufficient, and the tensile strength of the joint is improved. The fracture morphology of the No. 1 specimen is shown in Fig. 6.

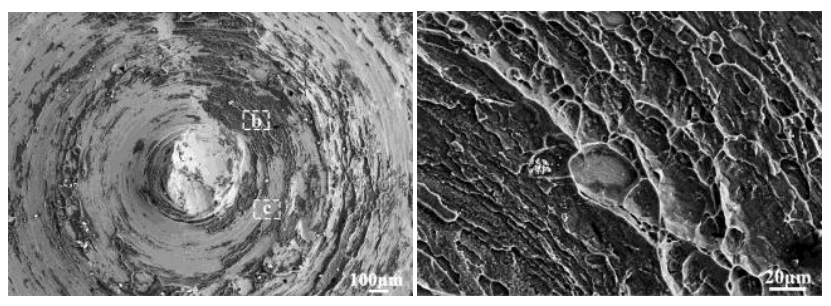

$\mathrm{a}$

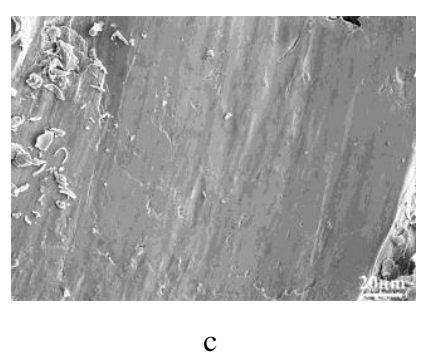

Fig. 6. SEM image of steel side fracture
Fig. 6 a shows the fracture morphology at a lower magnification. It can be seen that some of the residual aluminum is annular and still retains the state of rotational friction. Fig. $6 \mathrm{~b}$ and $\mathrm{c}$ shows the further enlarged morphology of region "b" and "c" in Fig. 6 a. The fracture mainly presents two forms, one is shown in Fig. 6 b, which is in the form of a dimple, which is unevenly distributed on the fracture surface, and the dimple is shallow and the tearing edge is small. This form is mainly due to the joint. The local joint strength is higher than that of the aluminum side base material, and the toughness fracture occurs on the aluminum side during the stretching process; the other form is as shown in Fig. 6 c, the surface is smooth and bright, and the frictional pressure is too small during the welding process. The contact is not tight enough, and the heat input is low, and the metallurgical bonding effect is poor, resulting in brittle fracture. The large area of the fracture is a smooth shape, which indicates that the fracture form of the joint with less frictional pressure is a brittle-ductile fracture mainly composed of brittle fracture.

Fig. 7 shows the microhardness distribution of the joint under two parameters. The maximum hardness values of the joints of the two sets of test pieces appear in the near side of the steel side, which are $414 \mathrm{HV}$ and $447 \mathrm{HV}$, respectively, which are higher than the steel side base metal. The emergence of the trend, first of all, due to a certain degree of diffusion of the metal on both sides during the welding process. With the increase of friction pressure, the element diffusion distance increases, and more brittle and hard intermetallic compounds (IMC) are formed.
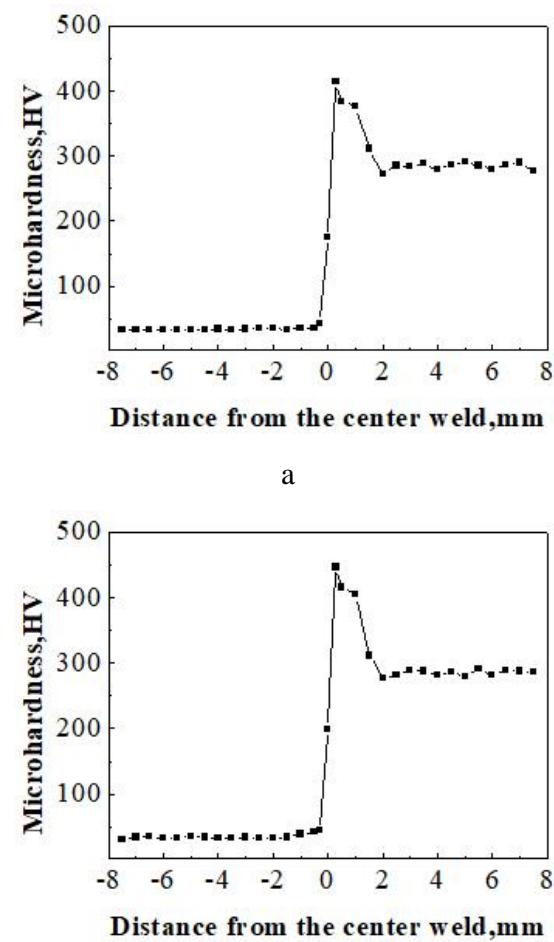

b

Fig. 7. Microhardness distribution: $a-$ No. 1 specimen; $b-$ No. 2 specimen

Secondly, during the welding process, there is a large frictional pressure and upset forging pressure between the contact faces, and the deformation strengthening [21] 
caused by the deformation and slip of the metal on both sides also increases the hardness. The maximum hardness of the No. 2 specimen is higher than that of the No. 1 specimen, which also proves that increasing the frictional pressure can promote the occurrence of diffusion and improve the mechanical properties of the joint.

\section{PURE ALUMINUM/304 STAINLESS STEEL INTERFACE IMC FORMATION PROCESS}

Some studies [22] had shown that the presence of excessive intermetallic compounds will reduce the performance of the joints. Therefore, it is important to understand the growth process of intermetallic compounds during friction welding. Combined with the above experimental analysis results, a growth mechanism model of intermetallic compounds was established, as shown in Fig. 8. In this study, two intermetallic compounds, $\mathrm{Fe}_{2} \mathrm{Al}_{5}$ and $\mathrm{FeAl}_{3}$, were found at the interface junction. It is generally accepted that the free energy of a compound is an important criterion for determining the growth order of a compound [22]. According to the literature [23], the Gibbs free energy of $\mathrm{Fe}_{2} \mathrm{Al}_{5}$ and $\mathrm{FeAl}_{3}$ is as follows:

$$
\begin{aligned}
& \triangle \mathrm{G}_{\mathrm{Fe} 2 \mathrm{Al} 5}^{0}=-253559+85.8 T \\
& \triangle \mathrm{G}_{\mathrm{FeAl} 3}^{0}=-142538+50.5 T
\end{aligned}
$$

When the temperature is lower than $660{ }^{\circ} \mathrm{C}$, the free energy of $\mathrm{Fe}_{2} \mathrm{Al}_{5}$ is lower than the free energy of $\mathrm{FeAl}_{3}$, so it can be inferred that $\mathrm{Fe}_{2} \mathrm{Al}_{5}$ is preferentially formed at the interface, followed by $\mathrm{FeAl}_{3}$.

The friction welding process can be generally divided into two main stages: the friction stage and the upsetting stage [15]. In the friction stage, the interface temperature is continuously increased, the atoms are fully activated and the interface structure is plasticized. Under the action of the axial pressure, the metal gap becomes small and a large number of dislocations are formed, and the atoms spread unevenly across the interface, but due to the high speed of the workpiece Rotation, the interface contact position changes constantly, and the plasticized aluminum alloy is continuously squeezed out of the interface, and the contact interface material is continuously updated, which causes the intermetallic compound to be difficult to nucleate and grow. At this stage, an iron-aluminum amorphous phase is formed. The amorphous phase is the "intermediate" [24] produced prior to the formation of the intermetallic compound, as shown in Fig. 8 a. At the end of the friction stage, entering the upset forging stage, the interface atoms are fully diffused under the higher upset pressure, a part of the amorphous phase gradually transforms into an intermetallic compound, and the other part remains in the interface, and at the same time, the unbalanced interdiffusion continues. Ironaluminium atom bonding preferentially forms $\mathrm{Fe}_{2} \mathrm{Al}_{5}$ with lower free energy, $\mathrm{Fe}_{2} \mathrm{Al}_{5}$ grows laterally after nucleation, and grows in the shape of tongue after being connected into a whole. Since the diffusion rate of iron-aluminum atoms in plasticized aluminum alloy is faster than that in solid steel, the growth of compound $\mathrm{Fe}_{2} \mathrm{Al}_{5}$ to the aluminum side is further More, as shown in Fig. 8 b. There are large vacancies along the c-axis direction in the crystal structure of $\mathrm{Fe}_{2} \mathrm{Al}_{5}$ [25]. Under the stress gradient caused by the elemental concentration gradient and the upset pressure, the steel aluminum atoms continue to diffuse through the $\mathrm{Fe}_{2} \mathrm{Al}_{5}$ layer, and the aluminum atoms on the aluminum side combine with $\mathrm{Fe}_{2} \mathrm{Al}_{5}$ to form a serrated [23] $\mathrm{FeAl}_{3}$, as shown in Fig. $8 \mathrm{c}$. At the end of the welding, the forging pressure disappears, the temperature rapidly decreases, the diffusion rate is greatly reduced, and the compound produced at the interface tends to be stable. As shown in Fig. 8 d, a serrated interface as shown in Fig. $3 \mathrm{c}$ is formed at the interface.

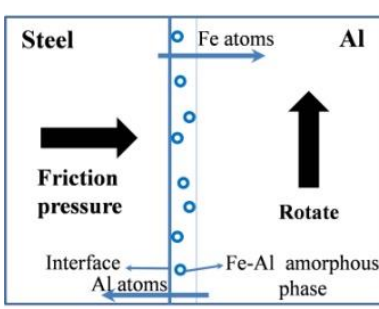

a

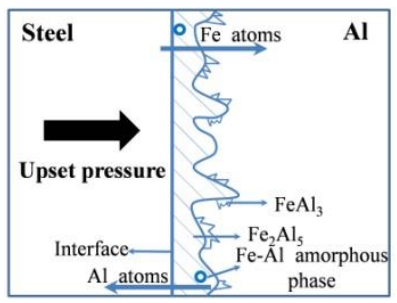

c

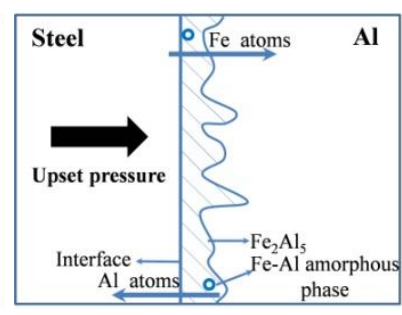

b

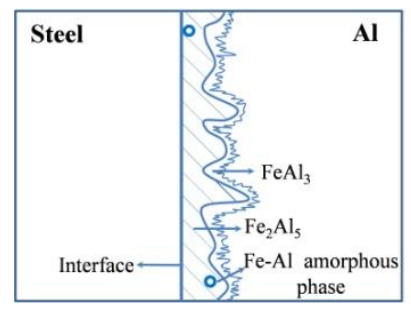

d
Fig. 8. Model of IMC generation process

\section{CONCLUSIONS}

1. Continuous driving friction welding can realize the effective connection between pure aluminum and 304 stainless steel. The joint flash is generated by the aluminum side, and the flash size increases with the increase of friction pressure.

2. The formation of $\mathrm{Fe}_{2} \mathrm{Al}_{5}$ and $\mathrm{FeAl}_{3}$ intermetallic compounds was found in the joints. The diffusion distance of elements can reach $1.9 \mathrm{um}$. As the frictional pressure increased, the element diffusion distance increased.

3. The fracture of No. 1 specimen broke at the interface, and the fracture form was a brittle-ductile fracture mainly composed of brittle fracture. Under the experimental conditions, the larger frictional pressure (1.7 $\mathrm{MPa}$ ) can improve the tensile properties of the joint, and the joint strength can reach or exceed the aluminum side base metal.

4. The maximum hardness of the joint of No. 1 specimen is $414 \mathrm{HV}$, and the maximum hardness of joint of No. 2 specimen is $447 \mathrm{HV}$. The increase of frictional pressure will increase the maximum hardness.

\section{Acknowledgments}

This work has been strongly supported by the Development and Reform Commission of Ji Lin, China and the Changchun Science and Technology Bureau. Meanwhile, I would like to thank Dinglan New Energy co., ltd. for its support of this experiment. 


\section{REFERENCES}

1. Tang, C.L., Guo, X.F., Xu, Q.P. Research on Browth Behavior of Intermetallic Compound at Al/Steel Bonding Interface Journal of Materials Science and Engineering 36 (05) 2018: pp. 29-35. https://doi.org/CNKI:SUN:CLKX.0.2018-05-005

2. Chen, S.J., Zhao, P.F. Steel/aluminum Diffusion Welding Technology and Microstructure of Dissimilar Metals by TLP Welding \& Joining 5 2013: pp. 32-35. https://doi.org/10.3969/j.issn.1001-1382.2013.05.007

3. Cui, L., Chen, B., Chen, L., Dual Beam Laser Keyhole Welding of Steel/aluminum Lapped Joints Journal of Materials Processing Technology 256

2018: pp. $87-97$.

https://doi.org/10.1016/j.jmatprotec.2018.02.016

4. Hasanniah, A., Movahedi, $M$. Welding of $\mathrm{Al}-\mathrm{Mg}$ Aluminum Alloy to Aluminum Clad Steel Sheet Using Pulsed Gas Tungsten Arc Process Journal of Manufacturing Processes 31 2018: pp. 494-501. https://doi.org/10.1016/j.jmapro.2017.12.008

5. Ye, Z., Huang, J., Cheng, Z. Study on Butt Joining 5052 Aluminum Alloy/Q235 Mild Steel by MIG-TIG Doublesided Arc Welding-brazing Process Welding in the World 62 2018: pp. $145-154$ https://link.springer.com/article/10.1007\%2Fs40194-017- 0516-Z

6. Wu, M.F. Study on Low Temperature Diffusion Welding of Aluminum Alloy and Stainless Steel and Diffusion Behavior of Main Components at Interface Jiangsu University 2011: pp. 1-121. (in Chinese)

https://doi.org/10.7666/d.y1895420

7. Zhang, L.N., Zhao, Y.H., Zhang, T.C. Microstructure and Mechanical Properties of Inertial Friction Welded Joint of 2219 Aluminum Alloy and Stainless Steel Electric Welding Machine 47 (11) 2017: pp. 100-105. https://doi.org/CNKI:SUN:DHJI.0.2017-11-039

8. Feng, J., Han, J., Zhang, X.M. Continuous Drive Friction Welding and Postweld Heat Treatment of 7A04 Aluminum Alloy/304 Stainless Steel Transactions of the China Welding Institution 39 (8) 2018: pp. 11-17. https://doi.org/10.12073/j.hjxb.2018390192

9. Sahin, M. Joining of Stainless-steel and Aluminium Materials by Friction Welding International Journal of Advanced Manufacturing Technology 41 (5-6)

2009: pp. $487-497$. https://doi.org/10.1007/s00170-008-1492-7

10. Ashfaq, M., Sajja, N., Rafi, H.K. Improving Strength of Stainless Steel/Aluminum Alloy Friction Welds by Modifying Faying Surface Design Journal of Materials Engineering and Performance 22 (2)

2013: pp. 376-383.

https://doi.org/10.1007/s11665-012-0278-0

11. Masaaki, K., Masahiro, K., Koichi, K. Friction Welding Technique and Joint Properties of Thin-walled Pipe FrictionWelded Joint between Type 6063 Aluminum Alloy and AISI 304 Austenitic Stainless Steel The International Journal of Advanced Manufacturing Technology 82 (14)

2016: pp. $489-499$.

https://doi.org/10.1007/s00170-015-7384-8

12. Zhong, Y. Numerical Simulation and Process Research on the Process of Dissimilar Metal Friction Welding Northwestern Polytechnical University 2006: pp. 1-84. (in Chinese).

https://doi.org/10.7666/d.y857911
13. $\mathbf{L i}, \mathbf{P} ., \mathbf{L i}, \mathbf{J} ., \mathbf{L i}, \mathbf{X}$. A Study of the Mechanisms Involved in Initial Friction Process of Continuous Drive Friction Welding Journal of Adhesion Science and Technology 29 (12) 2015: pp. $1246-1257$. https://doi.org/10.1080/01694243.2015.1022499

14. Kimura, M., Inoue, H., Kusaka, M. Analysis Method of Friction Torque and Weld Interface Temperature during Friction Process of Steel Friction Welding Journal of Solid Mechanics and Materials Engineering 4 (3) 2010: pp. $401-413$. https://doi.org/10.1299/jmmp.4.401

15. Zhang, C.Q., Liu, X.B., Lv, G.M. Friction Torque and Heat Input Characteristics During Continuous Drive Friction Welding of Aluminum to Steel Journal of Mechanical Engineering 54 (2) 2018: pp. 110-116. (in Chinese) http://www.cnki.com.cn/Article/CJFDTotal-JXXB201802017.htm

16. Li,W., Vairis, A., Preuss, M. Linear and rotary friction welding review International Materials Reviews 61 (2) 2016: pp. $1-30$. https://doi.org/10.1080/09506608.2015.1109214

17. Wang, B., Huang, J.H., Zhang, T.C. Effect of Pressure on Properties of Inertial Friction Welded Joint of FGH96/GH4169 Superalloy Transactions of the China Welding Institution 39 (4) 2018: pp. 41-44. https://doi.org/10.12073/j.hjxb.2018390092

18. Zhang, P.C., Bai, B., Zou, J.S. Pressure Effects on Be/HR-1 Stainless Steel Diffusion Welding Chinese Journal of Rare Metals 27 (2) 2003: pp. 233-237 https://doi.org/10.3969/j.issn.0258-7076.2003.02.004

19. Lin, S.B., Song, J.L., Yang, C.L. Microstructure Analysis of Interfacial Layer with Tungsten Inert Gas Welding-Brazing Joint of Aluminum Alloy/Stainless Steel Acta Metallurgica Sinica 45 (10) 2009: pp. 1211-1216. https://doi.org/10.3321/j.issn:0412-1961.2009.10.010

20. Fukumoto, S., Tsubakino, H., Okita, K. Microstructure of Friction Weld Interface of 1050 Aluminium to Austenitic Stainless Steel Materials Science and Technology 14 (4) 1998: pp. 333-338. https://doi.org/10.1179/mst.1998.14.4.333

21. Shang, X.W. Study on Friction Welding Technology and Temperature Field Simulation of Large Section Aluminum/Steel Lanzhou University of Technology 2010: pp. 1 -70. (in Chinese) https://doi.org/10.7666/d.Y1712681

22. Shi, Y., He, C.C., Huang, J.K. Thermodnamic Analysis of the Forming of Intermetallic Compounds on AluminiumSteel Welding Interface Journal of Lanzhou University of Technology 39 (4) 2013: pp. 5-7.

https://doi.org/10.3969/j.issn.1673-5196.2013.04.002

23. Cui, D.Z., L, S., Cui, Q.Q. Effect of Heat Input on Microstructure and Mechanical Properties of CMT WeldingBrazing Joint Between 5052 Aluminum Alloy and Galvanized Q235 Steel Transactions of the China Welding Institution 35 (9) 2014: pp. 82-86. http://www.cnki.com.cn/Article/CJFDTotal- HJXB201409020.htm

24. Fukumoto, S., Tsubakino, H., Okita, K. Amorphization by Friction Welding between 5052 Aluminum Alloy and 304 Stainless Steel Scripta Materialia $42(8)$ 2000: pp. $807-812$. https://doi.org/10.1016/S1359-6462(00)00299-2

25. Chen, M.J., Huang, J.K., He, C.C. Thermodynamic Analysis of Formation of Fe-Al-Zn Intermetallic Compounds in the Welding Interface Zone of $\mathrm{Al} / \mathrm{Galvanized} \mathrm{Steel} \mathrm{Plate}$ Acta Metallurgica Sinica 1 2016: pp. 113-119. http://www.cnki.com.cn/Article/CJFDTotal-JSXB201601015 